\title{
ENTRE O TECIDO FÍSICO \\ E SOCIAL DAS CIDADES \\ Entrevista com Sharon Zukin*
}

\section{Heitor Frúgoli Jr. e Julio Cesar Talhari}

Tradução de Lilian Gasparetti Abdoullah

* Transcrição (com revisão de Sharon Zukin e Heitor Frúgoli Jr.) e tradução para o português (com revisão de H. Frúgoli Jr. e Julio C. Talhari) de Lilian Gasparetti Abdoullah; nossos agradecimentos ao Núcleo de Apoio à Pesquisa "São Paulo: cidade, espaço, memória" (NAPSP-USP), pelos recursos à vinda de S. Zukin ao Brasil e à transcrição e tradução da entrevista, bem como a Alison Jane Francis, Bruno Puccinelli, Guilhermo A. Aderaldo, Laís Silveira, Márcio J. de Macedo e Weslei E. Rodrigues (ligados, com exceção de Francis e Macedo, ao Grupo de Estudos de Antropologia da Cidade, GEAC-USP).
A socióloga Sharon Zukin, professora do Brooklyn College e do Graduate Center da City University of New York (Cuny), tem sido há décadas uma forte referência em diversas áreas do campo dos estudos urbanos. Suas pesquisas, em boa parte centradas em Nova York, com interesses recentes em outros contextos, ${ }^{1}$ têm enfocado sistematicamente processos contemporâneos assinalados pela articulação entre paisagem urbana - em síntese, aquilo que "dá a forma material a uma assimetria do poder econômico e cultural" (Zukin, 1996a, p. 207) -, estratégias de produção do espaço, padrōes culturais e modalidades de consumo.

Pode-se mencionar, como uma espécie de marco inaugural, a notável abordagem sobre o bairro nova-iorquino do Soho (Zukin, 1982), em que antigos galpões industriais se tornaram residências de artistas no início da década de 1970 - com uma forte participação de mulheres, ligadas ao movimento feminista da época (De Salvo, 2001) - 
numa cidade naquele período em grave crise fiscal. A partir de então, artistas e intelectuais potencializaram novas experiências que levaram inclusive à patrimonialização histórica local. Todavia, isso também gerou uma valorização imobiliária e a atração de novos atores sociais com razoável poder aquisitivo, resultando inclusive na expulsão de boa parte daqueles que participaram da reinvenção daquela paisagem, em face da produção mercadológica de uma diversidade de outra ordem, em que predominam agentes ligados ao consumo cultural, à moda, à mídia, às galerias etc. ${ }^{2}$

Em seu último livro, Naked city (2010), Sharon Zukin basicamente volta o olhar atento às paisagens recentes de localidades arquetípicas nova-iorquinas e aponta uma configuração abrangente de forças homogeneizantes ligadas a intervençôes de reurbanização articuladas ao grande capital, o que suscitaria a sensação de uma cidade que, de forma vertiginosa, vai perdendo sua alma. ${ }^{3}$ Acontece que isso se combina a outros processos que repóem, sob a lógica do mercado, uma certa aura de autenticidade - presentes nas conjunçôes entre edifícios envelhecidos, galerias de arte, butiques, lojas familiares, restaurantes étnicos, mercados de rua etc. -, que dialoga com contextos mais tradicionais, mas que se pauta pela produção de uma diversidade sociocultural limitada - numa espécie de ampliação, sob distintas sínteses, do processo já analisado em Loft living (Zukin, 1982). Isso leva a autora a uma retomada crítica e retrospectiva da influência de Jane Jacobs (1916-2006), sobretudo do seu clássico The death and life of great American cities (1961). ${ }^{4}$ Apesar de toda sua defesa intelectual e militante de um modo de vida urbano que se opunha à homogeneidade dos subúrbios de classe média, da luta contra as intervençōes lideradas por Robert Moses $(1888-1981)^{5}$ e da defesa da diversidade das ruas, ${ }^{6}$ Jacobs teria, segundo Zukin, ignorado determinadas estratégias do grande capital - que inclui uma série de ressignificações da noção de autenticidade -, além de inspirar ações que, em última instância, mantiveram a diversidade de prédios e de usos, mas não propriamente a diversidade social urbana.

A autora, que já tinha vindo ao Brasil pela primeira vez em 1996, ${ }^{7}$ esteve em São Paulo em agosto de 2013, quando participou da conferên- cia internacional "Patrimônio cultural: memória e intervençōes urbanas", organizada pelo Núcleo de Apoio à Pesquisa "São Paulo: cidade, espaço, memória" (USP) ${ }^{8}$ e gentilmente cedeu-nos a entrevista que se segue.

Pergunta: Eu gostaria de começar com uma pergunta sobre o título do seu último livro - porque Nova York é possivelmente uma das cidades mais filmadas do mundo. Qual é a importância de Naked city (Zukin, 2010), 9 com base nessa perspectiva?

Sharon Zukin: Escolhi o título Naked city por causa do filme noir em preto e branco de $1948 .^{10}$ Esse foi o primeiro filme dos tempos modernos a ser produzido nas ruas da cidade e não em cenários especialmente construídos para esse fim. Aquela época do final da década de 1940 e o espaço da rua representam para mim um momento de autenticidade da cidade. Inclusive a reprodução da cidade - não em cores, mas em preto e branco - representa o contraste entre modernidade e tradição, entre a paisagem moderna imponente e o aspecto vernacular das comunidades sociais. Portanto, o título $\mathrm{Na}$ ked city, primeiro, representa a imagem cenográfica específica daquele período em Nova York e, implicitamente, refere-se a todas as grandes cidades modernas do fim do século XX. Havia também uma série policial chamada Naked city que emprestou o nome do filme. ${ }^{11}$ Tratava-se, no entanto, de algo completamente diferente. Toda semana havia uma história sobre um crime e a polícia o solucionava e, então, na semana seguinte, outra história, outro crime, tudo ficcional. No início de cada episódio, eles copiavam o narrador do filme, que dizia: "Há oito milhōes de histórias na 'Cidade Nua' e esta é uma delas". Eu gosto muito da representação textual que se vale de histórias de uma vizinhança e de espaços públicos para contar a história da cidade como um todo. Naquela época havia oito milhões de habitantes em Nova York, portanto, as palavras "oito milhões de histórias" sugerem que se podem contar muitas histórias diferentes. ${ }^{12}$ A terceira razão que me fez escolher esse título é que eu gosto do conceito de realismo da ideia original de Naked city: as imagens de um fotógrafo de cenas policiais feitas para um jornal. Seu pseudônimo era Weegee - 
seu nome verdadeiro era Arthur Fellig - e ele era famoso nas décadas de 1930 e 1940. Ele ia com a polícia em patrulhas e, se eles se deparassem com um homicídio, uma vítima de assassinato, ele tirava fotos do corpo e da cena do crime. Ele deu o título Naked city para uma coleção de suas fotografias. Então, a série televisiva copiou o filme, o filme copiou o fotógrafo e eu copiei todo mundo... [risos]

E há muitas cenas feitas na rua nesse filme, com muitas pessoas...

Sem dúvida. As ruas representam a autenticidade. Se você pensar nos filmes da década de 1960, todos eram em technicolor - eles começaram a romantizar e estetizar a cidade. Mas os filmes em preto e branco, para mim, representam a cidade real, as pessoas reais - uma imagem muito popular da cidade. O filme em preto e branco inclusive torna mais evidente o contraste entre os níveis alto e bai$\mathrm{xo}^{13}$ - na verdade, esse é inclusive o título de um filme policial feito em Tóquio pelo diretor japonês Akira Kurosawa ${ }^{14} \mathrm{em}$ que se podem ver os arranha-céus gigantes e as ruas comuns - para mim, essa também é a forma de mostrar a cidade real que estamos excluindo quando destruímos construções antigas e removemos pessoas das classes trabalhadoras, pessoas pobres para fora do centro das nossas cidades. E eu queria tentar capturar essa percepção no título Naked city.

$\mathrm{Na}$ introdução desse livro você tece várias criticas a uma figura central dos estudos urbanos nos Estados Unidos, Jane Jacobs, que em geral é vista de uma perspectiva otimista pela literatura da área. Qual é o propósito central da sua crítica?

Jane Jacobs formulou sua crítica em oposição à forma espacial das cidades modernas. Ela não se voltou à forma social das cidades. Como socióloga, primeiramente, considero que uma crítica da forma espacial é vazia, porque é apenas metade do caminho para a meta de se criar uma boa cidade. Agora, é possível que na sua época - a década de 1950, quando Jacobs fez a pesquisa para seu primeiro livro, Morte e vida de grandes cidades norte-americanas $(1961)^{15}$ - não parecesse haver o problema de deslocamento dos pobres. Na verdade, muito pelo contrário, naquela época os centros das cidades dos Estados Unidos estavam se tornando despovoados e empobrecidos de muitas maneiras, e a própria Jane Jacobs, como membro da classe média, contradizia o fluxo da população dessa classe social das cidades para os subúrbios. Portanto, talvez, ela sequer estivesse pensando que isso pudesse acontecer um dia, que o processo que agora nós conhecemos como gentrificação substituiria os pobres pela classe média.

Em segundo lugar, o início da década de 1960 foi a crista da onda das políticas de renovação urbana do governo federal. A demoliçãao de habitações e o deslocamento forçado dos residentes apresentavam a burocracia do Estado como o problema central. Era o Estado impessoal o responsável pela destruição do centro das cidades. Para nós, em um momento posterior, o problema central passou a ser as incorporadoras imobiliárias, os investidores privados que lucram com a mudança dos usos do espaço e com a remoção das pessoas que moram no centro. Então, para ser justa com Jane Jacobs, eu devo dizer: "Veja, talvez em sua época, a problemática era diferente da nossa".

Em terceiro lugar, no entanto, Jane Jacobs tinha uma política de comunitarismo, o que significa que ela não era de esquerda, mas ela também não era de direita. Esse tipo de política diz: "O Estado é um problema, e as pessoas devem resolver os problemas sociais elas mesmas". É por isso que Jane Jacobs diz que uma vizinhança precisa recriar a si mesma e tornar a se desenvolver. Sim, ela colocou sua fé em comunidades, não no Estado. Tenho certeza de que ela era democrática, de que ela tinha empatia pelas pessoas, mas sua política não era uma política de dependência do Estado; ela era categoricamente contra isso. Eu a encontrei uma vez, um ou dois anos antes de sua morte - ela havia ido a Nova York para fazer um seminário e dar uma palestra, e eu a conheci no seminário. Quando the perguntei o que ela sugeriria para ajudar pequenas lojas e pequenos negócios que estavam em risco de ser deslocados por conta do alto aluguel, ela não sugeriu uma mudança nas leis, que é o que eu proporia. Em vez disso, ela sugeriu que os pequenos negócios poderiam obter ajuda financeira para 
comprar seus prédios. De certa forma, isso é uma boa ideia, porque se você é o dono da sua própria casa ou edifício ninguém vai lhe expulsar, a menos que seja o Estado - você tem mais segurança. No entanto, apenas um ou dois anos depois, a grande crise hipotecária irrompeu nos Estados Unidos, e se todo mundo tivesse feito o que Jane Jacobs havia proposto, teríamos tido muito mais endividamento, uma crise de crédito ainda pior, e os donos de pequenas lojas que tivessem comprado seus imóveis não seriam capazes de mantê-los para si. Enfim, essa é a terceira razão: eu a critico porque ela rejeitou qualquer possibilidade de que o Estado pudesse mudar as leis ou assegurar uma situação melhor.

Por fim, em quarto lugar: Jane Jacobs não poderia prever que suas ideias se tornariam o dogma, a posição oficial dos governos das cidades e até mesmo das incorporadoras que diziam: "Ótima ideia, diversificar os usos, certo? Dar vitalidade às ruas, construir lojas, construir apartamentos em cima das lojas, trazer as pessoas para a rua, isso é ótimo". Ela não poderia ter previsto que seu argumento se tornaria a base da convicção de agentes ligados à gentrificação. Mas ela expressou uma crítica da monotonia estética e da falta de vitalidade da cidade que tais agentes sentiam. De novo, não podemos criticá-la, porque ela não sabia o que aconteceria no futuro. Porém, quando suas ideias se tornam um estímulo à gentrificação, observa-se então alguns resultados negativos a longo prazo para os residentes de uma vizinhança.

Recentemente, tenho feito uma pesquisa em uma vizinhança chamada Bedford-Stuyvesant que mostra que a gentrificação é um processo mais complexo do que havíamos pensado até agora. A população dessa vizinhança é majoritariamente negra, de origem afro-americana e caribenho-americana - pessoas que vêm da Jamaica, de Trinidad e de outros países insulares. Por vinte ou trinta anos, foi uma vizinhança de classe trabalhadora, classe média baixa e pobre. Foi ali, em um conjunto habitacional público, que Jay-Z, o rapper e empreendedor, nasceu. Mas algumas casas em Bedford-Stuyvesant são muito bonitas. Elas foram construídas no século XIX; eram residências enormes, feitas para a burguesia e mantiveram sua beleza, ainda que o bairro inteiro tivesse sido negligenciado pelo governo e pelos bancos e não tivesse sido tratado adequadamente. $\mathrm{O}$ crime era um problema sério, não como na "cracolândia", ${ }^{16}$ mas era bastante ruim: muitos roubos nas ruas e muitos traficantes, não tanto usuários, mas traficantes. Por muitas razões, com o passar do tempo, a criminalidade diminuiu - em toda a cidade de Nova York a taxa de criminalidade caiu bastante - e pessoas de outras regiōes começaram a olhar para as casas e dizer: "Nossa, elas são bonitas e baratas. Por causa da região desvalorizada, elas são mais baratas do que em outros bairros!”. Então, elas começaram a comprar as casas, e a vizinhança iniciou sua experiência de gentrificação. Por um lado, pessoas de alto nível educacional e profissional, homens e mulheres - negros, brancos e pessoas de várias origens étnicas - tornaram-se proprietários e gentrificadores. Por outro lado, estudantes e artistas - igualmente de raças e etnias diversas - alugaram apartamentos ali e também entraram na vizinhança como gentrificadores.

Aqui o processo se torna complicado de duas formas. Primeiro, os proprietários de longa data se beneficiam financeiramente dos valores mais elevados de suas propriedades caso queiram vender suas casas ou apartamentos. Portanto, eles tendem a ser a favor da gentrificação. Em segundo lugar, muitos dos gentrificadores nesse bairro são negros, especialmente entre os que compram casas. Mas os gentrificadores que não são negros tornam a população mais racialmente diversa. Muitos moradores de longa data gostariam de residir em um bairro étnica e socialmente diverso, mas não ao custo de perder o sentimento de pertencimento e de familiaridade que os afro-americanos e os caribenho-americanos criaram ali.

Você estabelece uma diferença muito clara entre o tecido físico e o tecido social das cidades (Zukin, 2010). Estamos falando sobre essa diferença?

Sem dúvida! A gentrificação é uma ótima estratégia para preservar o tecido físico da cidade: casas bonitas, ruas bonitas, usos variados, cafés, pequenas lojas. Mas os gentrificadores têm altos rendimentos se comparados com a maioria dos habitantes da cidade, então, eles alteram a economia local. Eles apoiam mercados de consumo cultural - cafés com 
nomes chiques em vez do café comum do dia a dia, restaurantes gourmet - mas não apoiam as pequenas lojas e as feiras livres das quais os residentes de menor renda dependem.

A questão do aluguel é muito importante. Algumas vizinhanças possuem organizaçōes comunitárias fortes, mas ainda assim elas não podem fazer nada a respeito dos aluguéis. Elas poderiam fazer protestos e manifestações nas ruas 24 horas por dia, mas isso não mudaria a lei. Antes de mais nada, propriedade privada é a lei suprema nos Estados Unidos, sem dúvida. Número dois: os alugueis na cidade de Nova York dependem das leis do estado de Nova York, então, ainda que a câmara municipal da cidade de Nova York dissesse: "Nós queremos mudar a lei do inquilinato" ou "Nós queremos controlar o valor do aluguel", eles não poderiam fazê-lo porque é a legislação do estado de Nova York que controla muitas cláusulas, incluindo o aluguel, de todas as cidades do estado. Nessa questão, a legislação do estado de Nova York não representa o interesse da maioria dos residentes da cidade.

Há dois anos, o então prefeito Bloomberg propôs que a cidade de Nova York adotasse uma tarifação de congestionamento do tráfego como há em Londres. Se você vai de carro ao centro da cidade, uma alta taxa é automaticamente cobrada. Em Nova York, muitas pessoas acharam isso uma ótima ideia, assim como eu. Mas as pessoas que moram nos subúrbios e vão para o centro da cidade de carro não gostaram. Bloomberg foi um prefeito muito influente e poderoso, mas não pôde fazer nada porque a legislação do estado de Nova York disse: "Não".

Ao contrário de Jane Jacobs, eu não penso que se deva focar em preservar o tecido físico da cidade por meio do estabelecimento de um bom planejamento. A única possibilidade de preservar o tecido social da cidade é controlar o acesso à moradia, o que, para muitas pessoas, significa controlar o aluguel.

Há alguma maneira de escapar dessa orientação mercadológica? Onde estão os espaços e projetos alternativos a essa realidade? Porque, de várias formas, muitas pessoas podem ser gentrificadoras sem ao menos saber disso.
Isso é, sem dúvida, uma verdade. Muitas pessoas tentam se organizar para lutar contra o poder do mercado, mas só vejo uma solução por parte do Estado. E como tentei explicar, é muito difícil enxergar a possibilidade política para que o Estado mude sua estratégia. Mas na cidade de Nova York muitas pessoas criticam o controle do aluguel. A cada ano, o número de apartamentos de aluguel controlado diminui e poucas vozes têm influência para evitar essa perda. Por outro lado, muitos nova-iorquinos fazem um apelo pela construção de mais moradias de preço "acessível". Mas o Estado não tem capacidade ou vontade de construí-las sem o setor privado. As autoridades municipais nos dizem que a lógica do mercado é que, se você controla os aluguéis, as incorporadoras não vão querer construir novas moradias. Muitas pessoas argumentam, portanto, que o aluguel controlado limita a oferta de novas moradias a valores acessíveis. Mas não concordo com esse argumento. Penso que se a perspectiva de incorporação muda, então as incorporadoras terão de construir de acordo com os critérios determinados pelo Estado.

Sou cética a respeito de certos tipos de resistência. Quando era estudante, tínhamos o movimento estudantil e, a despeito de todos os nossos esforços, eu percebia que os resultados disso, em nossa universidade, levavam a mais burocracia e a mais restriçôes. Além disso, iniciei minha vida profissional fazendo pesquisa em um país socialista - a antiga Iugoslávia (Zukin, 1975) -, onde as práticas reais de autogestão dos trabalhadores não eram democráticas e o regime de partido único não permitia dissidência. Isso é uma convicção muito pessoal, não posso dizer a outras pessoas que pensem da mesma forma, mas é importante levar em conta uma eventual traição da resistência pelo poder organizado. Não faço ideia de que tipo de resistência poderia funcionar melhor em Nova York, onde as incorporadoras, não o setor financeiro ou a mídia, são a indústria principal. Para mim, mudar as leis é crucial.

É por essa razão que escrevi Naked city como um livro sobre cultura e não sobre economia ou justiça social. Eu sabia que se falasse de controle do aluguel ninguém daria atenção. De fato, algumas pessoas leem o livro inteiro e quando veem as palavras "controle do aluguel", praticamente no fim 
do livro, atacam-no dizendo: "Esse livro que você escreveu é sobre controle do aluguel!". É ridículo, mas já disseram isso. Por outro lado, meus colegas de esquerda criticam o livro dizendo: "Esse livro que você escreveu é sobre cultura. Não sobre justiça social, mas sobre cultura. Quem liga para a autenticidade quando há injustiça?”. Mas, muito frequentemente, quando os críticos sociais discutem justiça social e o "direito à cidade", de Henri Lefebvre (1969), eles estão falando somente entre si. Na cidade como um todo as pessoas não querem saber.

Pelo fato de acompanhar processos de retomada de desenvolvimento por meio da observação daqueles que "herdaram" seu espaço na cidade e o reformularam para que refletisse seus próprios interesses e vontades, uso uma linguagem diferente. Tento usar o argumento cultural para persuadir as pessoas que são gentrificadoras, ou que podem ser gentrificadoras, de que elas deveriam estar cientes das consequências de suas ações.

Nós todos gostamos de diversidade social e cultural, mas as pessoas que personificam esse valor abstrato estão perdendo os espaços urbanos - as esquinas, as pequenas lojas familiares, os apartamentos de valor acessível -, onde culturas diferentes são reproduzidas. Os gentrificadores são, em geral, eleitores. Eles deveriam se manifestar pela mudança das leis de habitação, pelo estabelecimento de limites nos valores de aluguéis comerciais, para impedir que a gentrificação tome conta da cidade toda. Portanto, tento usar o argumento cultural para ganhar o coração e a mente dos gentrificadores.

De qualquer forma, seu livro recebe muita atenção e isso é um bom sinal, porque significa que há controvérsia e penso que seja importante discutir esses assuntos.

Para mim é sempre uma surpresa que Naked city desperte controvérsia. Quando as traduções sueca e italiana foram publicadas, houve ataques ao livro nos jornais nacionais de ambos os países. Não tenho certeza absoluta do que os críticos diziam, porque dependo de amigos e colegas suecos e italianos para uma tradução aproximada. Mas acredito que as críticas italianas foram escritas por jornalistas que haviam morado em Nova York e que admiram profundamente a vitalidade da cidade. Especialmente se eles visitaram Nova York entre a década de 1970 e o início dos anos 2000, eles se lembram das pichaçōes, dos imóveis abandonados, da epidemia de crack e das altas taxas de criminalidade. Tudo isso, em parte por causa da forte ação do governo na cidade, transformou-se em história - no caso da reabilitação das casas, um pouco por conta de uma maior atuação da polícia, um pouco por razôes que simplesmente desconhecemos. Também entendo que na Itália seja muito difícil mudar a cidade histórica em virtude de todas as leis de preservação dos monumentos e, com frequência, por causa da burocracia paralisante. A despeito desses fatores, há gentrificação em Roma, o que ameaça a reprodução das culturas autênticas da cidade, culturas locais que são parcialmente baseadas na região de origem dos residentes e nas relações de vizinhança existentes, e parcialmente, também, baseadas em suas classes sociais.

A propósito, Michael Herzfeld (2009) tem um livro sobre isso...

Evicted from eternity é um livro ótimo sobre a gentrificação de Monti, um bairro da cidade de Roma. Tenho uma amiga socióloga, chamada Irene Ranaldi, que escreveu um livro sobre o Testaccio, ${ }^{17}$ outro bairro de classe operária próximo a um antigo abatedouro, que tem sido transformado em um bairro hipster, alternativo, por assim dizer. Conforme diz uma reportagem sobre Testaccio em um site de viagens: "Artistas e açougueiros se misturam aos imigrantes e intelectuais, e todos comem muito, muito bem". Não estou certa de que muitos açougueiros ainda continuem lá! Essa é uma das mudanças culturais que analiso criticamente na cidade de Nova York, e os críticos literários de Roma deveriam saber do que estou falando! Em vez disso, eles elogiam Nova York por ser dinâmica e por estar sempre mudando e reclamam que tenho nostalgia da cidade antiga que estaria deixando de existir.

É interessante entender essas controvérsias.

Sim, os teóricos literários pós-modernos nos ensinaram que não só o autor, mas também os leitores são autores de um livro. Vi isso acontecer muitas 
vezes. Por exemplo, certa vez, um homem veio a um debate sobre um livro que editei com um amigo em 2002, After the World Trade Center (Sorkin e Zukin, 2002). ${ }^{18}$ Isso aconteceu praticamente um ano após o ataque terrorista ao World Trade Center no dia 11 de setembro de 2001, e as emoçôes ainda estavam à flor da pele. Esse homem queria muito fazer a primeira pergunta no workshop e quando pedimos que ele falasse, ele começou assim: "Minha esposa morreu no 11 de Setembro...”. É por isso que procuro entender a crítica ao meu trabalho em termos das preocupações e interesses subjacentes ao leitor. E é interessante perceber que pessoas veem sua própria cidade refletida nas minhas histórias de Nova York. Sou muito grata por isso.

Tenho escrito sobre Nova York há trinta anos. Cada vez que publico um livro sobre a cidade Loft living (1982), The cultures of cities (1995) ou Naked city (2010) - penso: "Ninguém vai se interessar porque fala apenas sobre Nova York". Na verdade, as editoras sempre dizem: "Não sei, esse livro é sobre Nova York. Talvez ninguém leia" [risos]. Mas é muito interessante perceber que há alguns problemas universais que as pessoas podem ver projetados no cenário de Nova York - problemas de crescimento, o problema dos ricos tomando a cidade, os problemas da perda do caráter da cidade, da perda de sua "alma", como eu digo, da perda da autenticidade. Talvez seja um pouco como a recepção bastante positiva que o livro magistral de Marshall Berman, Tudo que é sólido desmancha no ar ([1982] 1986), ${ }^{19}$ teve no Brasil, especialmente quando sua polêmica contra a destruição criativa modernista de seu antigo bairro ${ }^{20}$ pela construção de uma rodovia era relacionada com a crítica a Brasília.

Em algumas cidades, há uma problemática oposta, em que a destruição não é equilibrada pela criação de um espaço urbano novo. Em Detroit, há desinvestimento de capital, com o abandono de grandes áreas da cidade; Nova Orleans sofre de problemas similares. Mas Los Angeles e aquelas novas cidades da região oeste, talvez por terem uma organização espacial diferente, não podem viver exatamente a mesma coisa. Mas agora há gentrificação de alguns bairros mexicano-americanos em East Los Angeles - claro que Mike Davis em Cidade de quartzo ${ }^{21}$ já havia chamado atenção para a erradicação tanto das origens mexicanas de Los Angeles quanto de sua cultura de classe operária, que foi perdida na demolição do centro nos arredores de Bunker Hill. Penso que agora, em Los Angeles, eles estão começando a perceber a perda da autenticidade. Nós vemos os mesmos problemas em San Francisco, cujo controle de aluguel, como em Nova York, está sendo eliminado. Por causa do crescimento da indústria tecnológica, mais pessoas com muito dinheiro compram casas e apartamentos, provocando o deslocamento de artistas juntamente com operários e suas famílias. Todos esses são problemas que os nova-iorquinos conhecem. E, hoje, muitas cidades grandes ao redor do mundo enfrentam os mesmos problemas.

A propósito, o que levou você a Amsterdã? Estamos curiosos a respeito da sua pesquisa e dos resultados principais.

Quando terminei de escrever Naked city, comecei a desenvolver um novo projeto de pesquisa sobre ruas de comércio locais. Meu foco eram as pequenas ruas comerciais de bairros residenciais. Talvez algumas pessoas de fora façam compras ali também, mas essas ruas não são como as ruas do centro. Na maioria das vezes, trata-se de lojas comuns que satisfazem as necessidades do dia a dia, não são lojas grandes e especializadas. Quase sempre, você descobre que os pequenos negócios pertencem a proprietários individuais ou a famílias, não a corporações - em geral eles são imigrantes na cidade, vindos do mesmo país ou de uma região anexa, como um enclave, ou de muitos países diferentes; e dividem espaço na mesma rua. Já havia escrito sobre o papel das lojas nas mudanças nos bairros do Harlem e de Williamsburg em Naked city. Em outro capítulo, também escrevi sobre uma pequena rua de comércio em East Village. Não me lembro agora de como ou quando a ideia me ocorreu, mas pensei que poderia ser interessante ir a diferentes cidades para comparar a produção social desses espaços urbanos genéricos. Quem vai lá para começar um negócio? Como suas decisões individuais refletem sua vida e os padrões de migração de membros de seus grupos sociais e culturais? Como todas essas histórias individuais se juntam para criar a grande narrativa da rua e da própria cidade? 
Achei que seria interessantíssimo olhar para além da superfície das ruas comuns de comércio a face pública das comunidades locais - para ver como os grandes processos sociais são formados por muitas vidas individuais. E, você sabe, nós não damos o devido valor às ruas de comércio locais. É uma forma espacial e social muito importante da vida urbana. Ainda assim, não nos perguntamos como cada rua específica é criada, ou como elas mudam da dominância de um grupo social para outro.

A razão número dois para esse projeto de pesquisa foi: eu queria entender se nossa atual era da globalização cria espaços mais padronizados e homogeneizados ou se, pelo contrário, ajuda na diferenciação. Ouvimos esse argumento o tempo todo: "Quais são os efeitos da globalização?"; "A globalização destrói o local e impõe o global”. E de modo alternativo: "Ela oferece as ferramentas para que culturas diferentes se sustentem". Sempre me interessei por esta questão: "Os produtos culturais se tornam mais homogêneos? Ou se tornam mais diferenciados?”. As pessoas escrevem tanto a favor quanto contra esse assunto. Normalmente, digo que a globalização causa padronização, mas queria ver o que acontece nesse microespaço das ruas de comércio.

E a terceira razão é que eu tinha questôes analíticas muito específicas sobre a produção social da globalização, da migração e da gentrificação de baixo para cima, começando pelas ruas. Dizemos que vivemos numa era de globalização: a cidade é globalizada pelo fluxo transnacional de capital, fluxo de pessoas, fluxo de ideias. Mas queria estudar como isso acontece no dia a dia. "O que você vê? O que a globalização significa para o seu modo de vida? Como você vive a globalização nas suas experiências mais corriqueiras?"

Então, perguntei ao meu colega da City University of New York que estuda migração se ele trabalharia comigo nesse projeto. Decidimos incluir duas cidades da América do Norte, duas da Europa e duas do leste asiático. Fiz contato com pessoas que conheço em cada uma das cidades para que trabalhassem conosco como parceiros de pesquisa. Elas possuem o conhecimento local para fazer a investigação: falam a língua, conhecem as leis, entendem o contexto político, especialmente o que o
Estado pode fazer, e, frequentemente, lembram-se da história de ruas específicas e de como elas mudaram: demograficamente, como um local social e em relação a toda economia política urbana.

Gastamos muitos meses contatando as pessoas de formas variadas. Comecei falando com uma geógrafa em Toronto que já havia feito pesquisa com organizaçôes locais que representam os proprietários de empresas. Eu a conheci quando fui a Toronto para dar uma palestra, e ela me levou para ver algumas ruas de comércio locais que estavam mudando - algumas, por causa de gentrificação, outras, por causa da imigração. Quando visitei Xangai, conversei com geógrafos e sociólogos que conhecia em uma universidade de lá, e um colega de Connecticut, que também concordou em trabalhar comigo, falou com um sociólogo em outra universidade de Xangai. Quando fui às reuniōes da Associação Internacional de Sociologia, em 2010, em Gotemburgo, encontrei uma colega que eu conhecia de Tóquio e que também concordou em se juntar a nós.

Com isso, só faltava a Europa! Nós decidimos convidar sociólogos urbanos que havíamos conhecido em Berlim porque um deles havia estudado a integração social de migrantes em um bairro operário de lá. Justamente naquela época, tive a sorte de ser convidada para a cátedra de estudos urbanos como professora visitante na Universidade de Amsterdã por seis meses. O colega que me convidou estuda migração, ele já tinha alguns alunos de mestrado pesquisando uma rua de comércio específica, a Javastraat, no leste de Amsterdã, onde há muitos migrantes da Ásia Central. Para mim, escolhi estudar uma rua de alto padrão. Encontrei a rua Utrechtsestraat meio por acaso; a maioria dos proprietários de lojas fala um inglês excelente, e eu não falo holandês ou a maioria das línguas dos migrantes locais. É uma rua muito bonita que pertence ao Cinturão de Canais de Amsterdã, declarado patrimônio da humanidade pela Unesco - vou mostrar algumas fotos na conferência de amanhã. ${ }^{22}$ Depois de seis meses de observações etnográficas, de pesquisa histórica e de entrevistas com mais de vinte proprietários de lojas, escrevi um artigo sobre essa rua como uma forma de patrimônio cultural intangível (Zukin, 2012). 
Esse não é o tema principal do nosso projeto de pesquisa mais abrangente, mas por ter passado bastante tempo na rua, e por ter entrevistado vários pequenos empresários dali, foi possível o entendimento de uma rua de comércio local como um ecossistema cultural que dá suporte à ordem social de uma localidade. A sociabilidade entre os donos das lojas e os clientes, bem como a dependência mútua entre os lojistas, constituem dois fatores importantes. ${ }^{23}$ Trata-se da continuidade das lojas de propriedade independente, em contraste com as cadeias de lojas.

Devo salientar que decidimos limitar o projeto de pesquisa, nessa época, às cidades do "norte global” e do leste asiático. Já tendo publicado sete livros - somente considerando os três parceiros de pesquisa dos Estados Unidos -, sabíamos que um foco mais preciso tornaria o material mais claro e o livro mais atraente para as editoras. Além disso, entendemos que os estágios de desenvolvimento, hoje, são mais parecidos em nossas seis cidades, de Xangai a Nova York, do que em cidades do "sul global”. Também concordamos que os traços arquitetônicos das lojas são parecidos em todo o "norte global” e em Tóquio e Xangai também. No entanto, as ruas de comércio locais são muito importantes no mundo e são tão fascinantes no "sul global" para que sejam deixadas de fora do estudo. Então, estamos planejando um segundo livro. Depois de publicarmos um livro em conjunto sobre as seis cidades em que fizemos a pesquisa, vamos dedicar uma segunda publicação às ruas de comércio locais nas cidades do sul e da Ásia central.

A rua de alto padrão que estudei em Amsterdã, Utrechtsestraat, oferece um contraste real com muitas outras ruas de comércio na cidade e, especialmente, com Javastraat, que foi estudada pelos meus colegas da Universidade de Amsterdã. Na "minha" rua, há muito poucos proprietários de loja que sejam migrantes; e há muito poucos migrantes residentes naquele bairro do Canal. Embora não se possa notar isso hoje, essa rua passou por um processo de gentrificação nas décadas de 1980 e 1990. Agora, trata-se de uma área bastante cara. Os aluguéis estão subindo e mais lojas de alto padrão e lojas de comida "para viagem" modernas [trendy takeout food shops] estão abrindo. Essas são mudan- ças que estão ocorrendo desde que fui embora, em 2011. Os antigos moradores não gostam muito dessas mudanças. Eles apreciam a beleza da rua, gostam da qualidade excepcional e do refinamento do local. Às vezes, eles não fazem compras lá porque é muito caro, mas gostam da rua. É realmente uma rua muito bonita e até agora tem sido bastante diversificada em termos dos tipos de negócio que possui. Há três livrarias e uma especializada em literatura de viagem, uma revistaria, uma agência de viagens, dois coffee shops - em que é permitido vender pequenas quantidades de drogas "leves", como a maconha, com certas restrições. Há muitos cafés, algumas lojas de comida pronta que são excelentes, apesar de muito caras, duas padarias muito boas, duas boas lojas de queijos e açougues, embora não haja nenhuma loja de carne halal ${ }^{24}$ para muçulmanos.

Quando você pergunta às pessoas que possuem ou administram negócios nessa rua, se você pede aos moradores de longa data para que descrevam a rua, eles sempre dizem que amam a variedade e dizem que não é como a rua $\mathrm{X}$ ou $\mathrm{Y}$, onde há muitas lojas de rede ou as lojas são excessivamente chiques. Eles adoram essa rua porque ela é ao mesmo tempo exótica e familiar, eles a chamam de aldeia urbana por causa da escala humana das relaçóes sociais na rua: os comerciantes conhecem os clientes, e a rua não parece mudar. Mas agora está se tornando mais cara. E a quantidade de lojas de roupas e cafés excede o número de lojas de artigos do dia a dia. Suponho que eles paguem alugueis mais altos, mas se eles não têm clientes o suficiente, fecham após um ano, porque o fluxo de caixa é sempre um problema para pequenos negócios.

É muito interessante tentar entender Amsterdã por meio destas duas ruas: a rua dos migrantes e a rua de alto padrão. O contraste não é só demográfico e econômico, mas é também o contraste da política estatal. A rua de alto padrão é totalmente independente do Estado. Ela dependeu do Estado por dois anos por conta de reparos na rua e nas pontes sobre os canais, na infraestrutura. Claro, esse é um problema comum a toda rua de comércio. Se o governo da cidade fecha a rua para fazer reparos, os clientes não têm facilidade de acesso às lojas e os comerciantes perdem vendas. Então, os proprietários ficaram muito irritados com o governo municipal 
por dois anos e reclamaram e tentaram de tudo para que os reparos fossem finalizados o mais rápido possível. Mas, de fato, seus problemas eram irrisórios se comparados àqueles dos proprietários de lojas da outra rua, a rua dos migrantes, porque, nesse caso, o governo tem a política de integração social. Isso significa que o governo não quer muitas lojas de migrantes naquela rua e, então, eles fazem críticas: "Puxa, há muitos!". Eles não dizem "muitos negócios de migrantes", eles dizem: "Muitos problemas. É uma área problemática”. E então eles dizem: "Há muitas quitandas". Primeiro dizem: "Temos que trazer diversidade para esta área”. Trabalham por meio das cooperativas de habitação. Nos Países Baixos, ou especialmente em Amsterdã, as cooperativas de habitação são donas de grande parte dos prédios e criam a regra de que na rua Javastraat, aquela em que os migrantes são donos das lojas, os prédios devem renovar a fachada e, suponho, o interior dos prédios. Eles pressionam também os proprietários de prédios a fazer reformas. As reformas são caras, então, os proprietários precisam aumentar o valor do aluguel e alguns dos migrantes donos de lojas não conseguem pagar. Portanto, essa é uma estratégia. A segunda estratégia é: as cooperativas de habitação mudam o tipo de posse da propriedade, de forma que os apartamentos não estão mais disponíveis para locação, mas somente para venda sob a forma de escritura de posse individual [individual ownership apartments]. Muitos residentes migrantes não possuem o dinheiro para a compra, então as cooperativas de habitação os removem para outro apartamento em outro bairro. Isso de toda forma é melhor do que o que se faz em Nova York, porque lá ninguém ajuda ninguém a se mudar para outro lugar.

Em Amsterdã, as pessoas conseguem pelo menos outro apartamento, mas, ainda assim, são forçadas a sair de suas casas. Então, outra pessoa se muda para lá; em geral, são produtores culturais artistas ou professores. Muitos alunos e jovens professores mudaram para esse bairro, porque não é longe do centro e todos andam de bicicleta, fica a dez minutos de bicicleta da universidade, o que não é nada para um holandês. Além disso, os restaurantes desempenham um papel bastante curioso naquele bairro. Há ali um que recebe ótimas críticas nos jornais, até mesmo no New York Times ele foi mencionado duas vezes. É simbolicamente interessante, porque o nome desse restaurante é The wild boar. ${ }^{25}$ Ora, há muitos muçulmanos morando ali. Como pode haver um restaurante com o nome vinculado a porcos? No entanto, os muçulmanos não frequentam esse restaurante, não é o tipo de lugar para essa clientela, mas um lugar para pessoas que têm outro tipo de capital cultural. Um dos pesquisadores holandeses entrevistou o dono desse restaurante e ele disse: "Temos uma ótima relação com nossos vizinhos". Ok, eles têm boas relaçôes, mas o nome em si do restaurante é diferente, é um desafio para os vizinhos habitantes daquele bairro.

Portanto, há um contraste entre essas duas ruas de compras. Estamos próximos de lançar o livro e esperamos que os leitores acessem o site e coloquem fotos, mapas, entrevistas sobre as ruas de comércio de seus bairros de forma que possamos construir uma comunidade que aprecie essa forma urbana e que talvez - como havíamos falado de resistência - possa proteger a diversidade dessas ruas locais de comércio.

Não falei nem por um momento sobre alguns dos outros perigos para as cidades como rede de lojas, shopping centers, problemas de crédito para os pequenos lojistas e produtos de grife. Os jovens, por exemplo, não querem ir à rua de comércio local, ou, se houver uma butique, é cara demais para eles. Ao menos nos Estados Unidos, eles querem ir à loja mais barata que venda calças jeans de marca, e a rua de comércio local para eles não significa nada. Quando ficamos um pouco mais velhos, talvez, começamos a apreciar a rua de comércio local, e acredito que isso seja universal. Tenho a meta política de tentar preservar não só a diversidade étnica e social das ruas de comércio local, mas também quero protegê-las como forma urbana - tanto social quanto espacialmente.

Há em Nova York mudanças em muitas ruas de comércio local por causa das compras virtuais, pela internet. De computadores a máquinas de lavar, de televisores a roupas, sapatos, pode-se comprar qualquer coisa pelo computador. Então, restam lojas que oferecem produtos e serviços que não se pode comprar pela internet: salão de beleza próximo a uma academia, ao lado de lojas de comida pronta, ao lado de uma pizzaria, próxima de um restaurante, 
ao lado de um café etc. Você perde muito da cidade quando existem apenas serviços assim.

$\mathrm{Na}$ rua de comércio local mais próxima da minha casa é a mesma coisa. Moro perto de uma universidade em que os alunos têm algum dinheiro; então, todo negócio novo na minha rua de comércio local nos últimos dois anos foi ligado a restaurantes. Você anda na rua e vê um restaurante italiano ao lado de um chinês, ao lado de um vietnamita, próximo a um restaurante mexicano, próximo de algum outro. Quando mudei para lá, há muitos anos, havia a padaria, o açougue. Já era bastante turístico, porque moro em Greenwich Village, mas ainda havia lojas locais de comida para as pessoas locais e dois pequenos supermercados. Agora, temos um grande supermercado especializado em comida orgânica e, como todo mundo vai lá, um dos pequenos fechou. Pude perceber as mudanças uma a uma. Universitários não se importam, eles vivem ali por quatro anos, para eles é ótimo, eles podem sair para comer, encontram serviços para suas necessidades. Mas entendo as mudanças estruturais na economia, entendo o que as compras on-line fazem com o espaço físico das cidades.

Você poderia falar sobre sua pesquisa em Xangai? Haveria nesse caso um modelo diferente de urbanização?

Não exatamente. As cidades na China seguem uma lógica de crescimento econômico similar à de São Paulo e Nova York - talvez não à lógica de Amsterdã. O centro da cidade tem sido transformado em Pequim e em Xangai a partir de suas formas espaciais tradicionais para o desenvolvimento vertical, com o desenvolvimento dos arranha-céus. $\mathrm{Na}$ China, o governo municipal é um parceiro no desenvolvimento. Nos Estados Unidos, ele é o facilitador do desenvolvimento privado, mas, como disse, na China, eles são parceiros, fazem dinheiro por meio da transferência das terras. Talvez os terrenos ou as propriedades não sejam vendidos, talvez eles façam apenas contratos de leasing imobiliário. De qualquer forma, o governo municipal ou distrital recebe benefícios econômicos diretos desse desenvolvimento. E, claro, em termos da imagem da cidade, eles a querem moderna; e eles têm o capital para investir na cidade. Querem criar essas cidades globais baseadas na imagem espetacular de arquitetura, e, de fato, é espetacular ver as fotos de Xangai. Você diz: "essa é a capital do século XXI", assim como Nova York foi a capital do século XX e Paris, a do século XIX. Quando fui a Xangai pela primeira vez, vi todos aqueles edifícios altos e novos - alguns deles são muito bonitos e, sem dúvida, espetaculares, muito imponentes e enormes.

Pequim ainda tem grande parte de seu centro ocupado pelos prédios da administração pública. Imagino que deve haver uma lei ou uma espécie de lei informal que impeça a construção de prédios muito altos próximos aos prédios do governo. Há muitos prédios altos, mas eles não estão exatamente no centro; na verdade, tanto em Pequim quanto em Xangai, novos centros financeiros foram construídos fora do centro histórico. Compreendo isso, pois os terrenos provavelmente são mais baratos e as áreas são relativamente mais disponíveis - o que chamaríamos, nos Estados Unidos, de greenfield development: áreas em que há fazendas e onde os terrenos são relativamente baratos. ${ }^{26}$ Os novos centros financeiros, em Xangai e em Pequim onde estão todos os escritórios corporativos - são, em ambos os casos, fora do centro histórico. Portanto, o modelo me parece ser exatamente o mesmo - os terrenos e a produção do espaço urbano são os mecanismos básicos do crescimento econômico - com a diferença de que o governo local está ainda mais interessado no desenvolvimento do que em Nova York, por exemplo. Em Xangai, na parte mais central da cidade, você ouve as pessoas falando inglês, mas se vai um pouco adiante, ouve mandarim [Putonghua Chinese] - chinês -, e mais para a periferia, você ouve o dialeto xangainês - um dialeto de Xangai -, o que significa que as pessoas locais sentem que foram deslocadas para a periferia. Mas, de novo, é complicado, porque os prédios antigos no centro estão em péssimas condições, e muitas cozinhas são comunitárias, o chão é de cimento, não de madeira. O aquecimento não é muito bom, o ar não é tão bom. Cozinhas e banheiros são coletivos. Eles têm o que chamam de hútòng - são becos, pequenas vielas e pequenas casas juntas - o ar não circula. Entendo que talvez a pessoa queira uma casa melhor, um apartamento melhor, mas ninguém quer que essa casa melhor 
esteja a $20 \mathrm{~km}$ de distância, em um bairro totalmente diferente. Portanto, o modelo de desenvolvimento urbano na China é diferente do que nos Estados Unidos ou na América Latina, mas não totalmente diferente.

Para mim, tem sido fascinante ver como as pessoas locais criam suas próprias formas urbanas em Xangai. Estive lá em junho deste ano [2013] para visitar uma das áreas de pesquisa do projeto. Em Xangai, tradicionalmente, por causa do clima quente, as lojas ficam abertas até tarde da noite, talvez nove, dez horas. Aparentemente, não há estrangeiros, mas há muitos donos de loja migrantes. Muitos deles vieram de outras partes da China e isso é histórico - Xangai sempre recebeu muitos migrantes das províncias próximas e ao redor. Se você anda pela rua e fala com os donos de loja, descobre que eles vêm dessa ou daquela província e, às vezes, eles contratam funcionários de suas próprias províncias, os quais conhecem por meio de suas relações sociais. Os donos de lojas por vezes moram atrás da própria loja e, às vezes, oferecem moradia para seus funcionários, o que é interessante.

Mas naquela rua específica, que fica em um bairro operário, não há lojas de comida. Há alguns restaurantes simples, sem nada de especial, como fast foods, por exemplo - não McDonald's, Burger King ou KFC, de outros tipos. Então, perguntei: "Onde estão as lojas de alimentos? Onde as pessoas compram comida?". E eles disseram: "Vamos aqui perto, tem um supermercado grande, o $\mathrm{Au}$ chan." - uma rede de hipermercados francesa, que abriu ali uma loja na década de 1990. Exatamente como no meu bairro em Nova York: assim que o grande supermercado abriu, todas as lojas de comida fecharam, todo mundo comprava comida lá. E há muitas pessoas que moram naquele distrito em torno de 200 mil pessoas, mais do que em qualquer outro distrito de Xangai. Claro que é um ótimo lugar para abrir um hipermercado. Entrei ali rapidamente e eles têm de tudo, todo tipo de mercadoria que se possa querer, incluindo artigos de vestuário.

A outra rua de comércio fica em um distrito diferente, mais próximo do centro; não é exatamente uma rua de compras, é o chamado parque da indústria cultural. A estratégia do governo lo- cal foi a de preservar os prédios antigos e as antigas moradias - predinhos de três ou quatro andares naquela rua em que moram os trabalhadores, o que contrasta com o restante daquele distrito que foi demolido e cujas casas antigas deram lugar a prédios de apartamentos extremamente caros ou a edifícios comerciais e lojas caras.

É muito incomum que, em Xangai, alguém tivesse tido a ideia de atrair artistas, como em Soho, para preservar o espaço, o tecido espacial e social dos residentes locais. No entanto, um homem teve essa ideia: ele visitou Nova York, foi ao Soho - conhecido como bairro da comunidade artística, que já não é mais um bairro artístico, mas era ainda há um ano - e teve a ideia de transformar as pequenas fábricas antigas, as pequenas oficinas em espaços de arte com a intenção de transformar aquela área em uma espécie de Soho, e que agora se chama Tianzifang. Esse foi o modo pelo qual os edifícios foram preservados - não como monumentos, mas como um bairro cultural em que os residentes de longa data permaneceram em suas casas.

Trata-se de uma forma particular de configuração...

Exatamente. Mas era diferente, porque havia oficinas lá, não só casas, e esse homem persuadiu os outros a partilhar da sua visão sobre o bairro. Ele falou com empresários de Xangai, alguns deles estrangeiros, artistas xangaineses... eles criaram um pequeno bairro artístico. Algumas galerias de arte foram abertas ali e, nas proximidades, há alguns escritórios de arquitetura e de design, de design gráfico e assim por diante, ao longo da rua. Em poucos anos, Tianzifang se tornou uma rua famosa; as pessoas querem ir lá tanto de Xangai quanto estrangeiros e, também, expatriados que moram em Xangai. Bares e cafés também foram inaugurados e a mídia passou a escrever sobre essa rua.

Visitei o local pela primeira vez como uma turista urbanista em 2007, porque havia lido sobre a rua e também porque um colega de Xangai, geógrafo, havia dito: "Você precisa conhecer essa rua, é muito interessante". O irmão dele é artista e tinha um estúdio lá. Mas, entre 2007 e 2011, houve uma expansão, porque não se trata de uma 
rua apenas, são essas áreas de hútòngs em que você adentra um portão e, então, há pequenas vias que conectam uma rua a outra, vielinhas, todas parte de um único, pequeno bairro, como acontece em algumas cidades do leste da Ásia. Você pode passear por ali, mas o espaço é fechado, cercado por paredes. Portanto, agora, não é mais somente aquela única rua, mas todas as ruas ao redor e, hoje, há talvez em torno de duzentos cafés e bares, e por aí vai. É muito interessante, porque você pode dizer: "Puxa, isso é Xangai!", mas, ao contrário, parece global. No entanto, agora, os alugueis estão começando a subir, e os donos de estúdios de arte daquela fase inicial estão achando muito caro, e as primeiras lojas também. Eles dizem: "Não é mais o que pensávamos”. Portanto, para mim, essa é uma história muito familiar da cidade.

Mas esqueci de mencionar uma coisa: em Xangai os residentes proprietários dos apartamentos térreos, muito frequentemente, constroem lojas na parte de fora de suas casas, ilegalmente. O governo municipal não os pune, isso é tolerado, mas o espaço da loja é ilegal - em Nova York isso jamais aconteceria. Portanto, eles constroem um espaço ilegal e cobram aluguel, o que faz com que consigam permanecer na área. Eles mesmos, possivelmente, são trabalhadores braçais, mas, ao mesmo tempo, são empreendedores, pois constroem a loja na parte da frente das casas e ganham o dinheiro do aluguel, embora, na verdade, não sejam donos dessas lojas. Em alguns casos, eles mesmos começam o negócio e, talvez depois de alguns anos, vendem a loja.

"Há um modelo diferente de urbanização?". De alguma forma, o modelo geral é o mesmo, mas há essa tolerância e o uso da informalidade, que acho muito diferente, e isso é verdadeiramente incrível. Todo mundo sabe disso em Xangai, não é nada de mais. Contudo isso mostra os limites do Estado. É realmente muito interessante, porque isso dá vida à rua, permite que se ofereçam os serviços e produtos necessários e dá emprego para as pessoas. Mas essas são duas ruas de tipos muito diferentes. Para mim, tem sido valioso analisar tanto a ação do governo municipal, da administração local, quanto a ação dos empreendedores informais na criação da cidade.
Os museus são, historicamente, espaços institucionais em que representaçôes e narrativas de naçōes, povos e cidades também são criadas. Recentemente, por conta da expansão da indústria turística em algumas cidades globais, os museus têm sido vistos e usados também como locais de consumo. ${ }^{27}$ Portanto, como esse novo uso dos museus afeta seu papel de produtores dessas narrativas e representaçōes?

Talvez possamos pensar nos museus como plataformas de mídia - como dizem no mundo da mídia -, um lugar onde narrativas não sejam apenas produzidas, mas, também, transmitidas. Portanto, assim como as pessoas consomem a mídia, elas consomem esses espaços. Talvez isso crie um tipo de público diferente de antes, ou talvez continue o mesmo de sempre, porque historicamente, como sabemos, o objeto das estratégias dos museus é o público. Quando os museus foram criados na Europa como museus públicos no século XIX, sua missão era civilizar a população, apresentar uma narrativa da nação e do comportamento: o indivíduo e a nação, o indivíduo que poderia contemplar os trabalhos de arte, mais do que desafiá-los ou criar novas formas de arte. Talvez, hoje em dia, trata-se de um público consumidor, e o museu, em muitos casos, está em paralelo com o shopping center.

Os lugares de memória, sobre os quais estávamos falando, são diferentes. Nós os chamamos de museus, mas, talvez agora, haja mais diferenciação entre tipos de museus. Os pequenos museus científicos que você encontra em alguns lugares são diferentes, eles ainda são muito especializados, e atraem um público diferente daquele que gosta de visitar grandes museus que sejam enciclopédicos ou bastante conhecidos por suas grandes coleções de arte moderna - e claro, todos contam com uma loja de souvenir para se levar algo para casa, mesmo que não se possa adquirir a Mona Lisa... No entanto, todos os grandes museus se tornaram catedrais do consumo, de muitas maneiras.

Mas, novamente, é complexo e, de alguma forma, os museus sofrem os mesmos problemas financeiros das cidades: eles precisam fazer dinheiro. Ao menos nos Estados Unidos, o Estado não quer ou não pode pagar todas as despesas - gastos mili- 
tares, a polícia, os bombeiros, as escolas. Tudo tem se tornado muito caro e todos nós esperamos corretamente, penso eu - que o Estado vá fornecer esses serviços. Contudo, por uma razão ou outra, especialmente com a recessão econômica em andamento, o Estado considera difícil levantar o dinheiro necessário.

Se você vai ao Museu de Arte Moderna de Nova York (MoMA), que é um museu privado, você paga caro: 20 ou 25 dólares. Mas, claro, para legitimar o valor do ingresso, eles oferecem muitos espaços diferentes no museu: dois restaurantes, cinema, todas as galerias. Dá para passar o dia todo lá, certo? Então, você pensa: "Bem, 20 dólares? É, eu deveria ficar o dia todo lá". Os grandes museus têm o mesmo tipo de organização ou lógica de qualquer outra empresa: crescer. Qual é o foco de uma empresa? Sobreviver e crescer. Os museus de arte precisam disso em especial: eles têm muitas peças, porque precisam continuar seu acervo, o que é parte de sua missão. Portanto, eles têm mais e mais obras que precisam expor, afinal, o negócio deles é expor. Mas é preciso pagar por isso - bem, falo dos museus maiores e mais ricos, estou certa de que isso não é verdadeiro para todos os museus.

Vejamos o caso de Nova York: há o Museu Metropolitano de Arte (Met) e o Museu de Arte Moderna (MoMA) - claro que temos outros museus, mas esses dois se tornaram museus imperiais. $\mathrm{O}$ primeiro, ao longo do tempo, tem construído mais salas e mais galerias se expandem tomando o Central Park. É verdade que esse parque é enorme e que o museu é apenas uma pequena parte dele, mas, enfim, o museu vai crescendo. O MoMA fica em uma rua no centro da cidade e se expande comprando propriedades ao seu redor. No último ano, ele comprou o prédio de um outro museu do outro lado da rua, porque este estava ficando cada vez mais pobre. Era um pequeno museu, muito bonito, especializado em design, mas, cada vez mais endividado - isso é o que se vê nos museus. É como o que se vê com os times de futebol: alguns se tornam extremamente ricos e internacionais, com estrelas internacionais, outros são muito pobres.

Sim, estava pensando exatamente nessa lógica enquanto você falava...
Sem dúvida, concordamos nesse ponto. Portanto, o MoMA é dono de seu pequeno quarteirão e se expande, toma mais espaço. Há um prédio residencial próximo ao museu - não tenho certeza, escrevi sobre isso há muito tempo em The cultures of cities (Zukin, 1995) -, não sei exatamente qual é o tipo de contrato de propriedade ali, mas o museu lucra com aquele prédio e os apartamentos são muito caros, bilionários estrangeiros moram lá. Recentemente uma empresa francesa de cristais de luxo, a Baccarat, construiu ali uma torre de hotel e de apartamentos condominiais, então a $53^{\text {rd }}$ tem se tornado o império cultural do MoMA. Há também uma unidade da Biblioteca Pública de Nova York; claro que essa biblioteca sempre teve problemas para levantar fundos - trata-se de um sistema de bibliotecas ótimo, fabuloso e gratuito para todos, mas precisa fazer dinheiro para manter as unidades abertas, para pagar os funcionários. É realmente uma das melhores coisas das cidades norte-americanas, sem dúvida, ou pelo menos de Nova York e da Filadélfia - acho que todas as cidades norte-americanas têm um sistema de bibliotecas públicas. Enfim, a biblioteca entrou em uma parceria com a Baccarat Hotel and Apartments. Agora, eles não precisam fazer dinheiro, mas a incorporadora do prédio residencial vai construir um novo espaço para a biblioteca ali. Dessa forma, aquele quarteirão inteiro é, como eu disse, um pequeno império do MoMA.

O 11 de Setembro ${ }^{28}$ foi um evento dramático que marcou a entrada de Nova York em uma nova era para as cidades globais no que diz respeito a assuntos como terrorismo, segurança e vigilância. Você já mencionou o livro que organizou com Michael Sorkin a esse respeito. Como os nova-iorquinos lidam, de um modo geral, com o 11 de Setembro doze anos depois? Isso ainda é relevante para a cidade em termos de dinâmica social?

Primeiramente, agradeço por esta pergunta, porque esse foi um trauma realmente importante para Nova York. Devo dizer que muitas cidades ao redor do mundo estão em estado de guerra, cidades em que os cidadãos se tornam vítimas inocentes de ataques militares e da ocupação militar. Então, 
Nova York, desse ponto de vista - não sei como dizer isso da forma correta - em comparação com outras cidades, sofreu no 11 de Setembro, mas não sofreu tanto quanto algumas cidades continuam sofrendo todo dia.

Para nós, foi um trauma e continua sendo um trauma - uma sensação de que estamos constantemente sob algum tipo de ataque. Acredito que muitas pessoas não querem pensar nisso todo dia. Sei que penso sobre isso e não sou, em geral, do tipo de pessoa paranoica. Mas as pessoas em Londres ou em Madri, quando pegam o metrô, devem estar pensando a mesma coisa. Em algum nível de consciência você está ciente disso. Não sei se os jovens, os que não viveram o 11 de Setembro, se eles sentem o mesmo que eu.

Somos constantemente lembrados, temos avisos que dizem: "Se você vir alguma coisa, fale alguma coisa" - o que significa que se você vir um pacote, mas ninguém ao lado dele, talvez seja uma bomba, então, você deveria procurar por um policial e falar com ele. Claro, que, às vezes, não há policiais no local.

Isso cria um certo clima de paranoia permanente. Há patrulhas ocasionais da polícia, e eles revistam pacotes no metrô. Isso se tornou uma parte normal da vida da cidade agora - não uma parte normal boa, mas uma parte normal da vida urbana. Há uma espécie de vigilância. Mas muitas pessoas que não perderam familiares ou amigos, talvez, elas queiram esquecer. E isso não é uma coisa errada, porque você fica louco se pensar nisso todo dia. "Será que essa pessoa do meu lado é terrorista?". Você não quer pensar nisso. E, então, claro, há o perigo de julgar as pessoas de acordo com certos estereótipos: "Bom, essa pessoa é muçulmana..." Você não quer fazer isso. Penso que a maioria dos norte-americanos e certamente as autoridades estão muito conscientes de todos esses perigos.

Enfim, acho que muitas pessoas tentam esquecer. A crise econômica, a recessão dos últimos anos, penso, pode ter um efeito no aumento das taxas de criminalidade. Por dez anos depois do 11 de Setembro, creio que houve um sentimento coletivo de unidade, de que fomos nós todos atacados. Acho que isso pode ter tido um efeito de diminuição nas taxas de criminalidade. Se todos estão sob ataque, você não vai atacar o próximo. Havia uma extrema solidariedade nas semanas após o 11 de Setembro e diria que isso perdurou bastante tempo. Mas, depois, é como a ditadura militar, o terrorismo do Estado, depois de alguns anos a memória se torna mais pálida. O que se pode fazer? Falar de terrorismo para bebês? É uma coisa difícil. Você não quer criar um trauma permanente.

E quanto às construçōes no Ground Zero ${ }^{29}$ ? Você falou sobre a possibilidade de fazer algo diferente em termos de paisagem urbana (Zukin, 2002), mas isso efetivamente não ocorreu.

Não, não ocorreu. Bem, aquela área de Lower Manhattan inclui o centro financeiro de Wall Street, a nova comunidade chamada Battery Park City e a região cara do TriBeCa. Trata-se da área residencial que mais cresce na cidade de Nova York, mas o governo estadual não queria desistir da função financeira do local do World Trade Center. Ele, que na verdade controla os terrenos ali, direta e indiretamente, não queria mais empreendimentos residenciais e exigiu a reconstrução de prédios comerciais. A decorrência imediata após o trauma era não mudar. O prefeito Bloomberg, na verdade, disse: "Observem o que está acontecendo, prestem atenção ao mercado imobiliário, deve ser residencial, não comercial", mas sua decisão foi recriar edifícios comerciais.

Para mim, nada deveria ser construído imediatamente, simplesmente deveria ser deixado quieto por um tempo. Mas esse é outro problema, porque há competição por capital de investimento. Em qualquer cidade grande, todo mundo precisa atrair investimento. Construir escritórios na área do World Trade Center coloca aquela área em competição com uma área em Manhattan, chamada Hudson Yards, e com outra em Brooklyn, chamada Atlantic Yards, e quem sabe com quais outras. No entanto, há o problema, agora, de quem vai alugar esses escritórios, porque há escritórios disponíveis em outros distritos. Esse foi um conflito interessante.

O segundo conflito foi: "Que tipos de centros de cultura, espaços culturais nós construiremos lá?”. Não havia propósito em construir espaços culturais para a classe trabalhadora, porque a classe 
trabalhadora não mora lá. Escrevi algumas páginas sobre esses conflitos em Naked city: "Construímos um museu?"; "Ah, ótimo, vamos construir um museu!"; "Que tipo de museu?"; "Vamos construir um museu em memória dos acontecimentos trágicos do ataque terrorista". "Bem, que tipo de museu poderia celebrar a homenagem a essa memória?”; "Bem, nós celebramos a democracia americana!"; "E como celebramos a democracia?"; "Como decidimos o que colocar no museu?". Isso provocou uma série de conflitos e, então, surgiu a ideia do memorial: "Ok, queremos um memorial". Houve muitos conflitos sobre o design do memorial. Visitar o museu se torna uma questão importante, muitas pessoas querem visitar, compram o ingresso etc. Mas se você entra em um espaço público como aquele, suas coisas são revistadas. É preciso, evidentemente, ter vigilância e tudo o mais. Assim, há o museu e o seu próprio conflito, o memorial e seus próprios conflitos. Por fim, talvez em dez anos, tudo ficará bem e então veremos o que será construído ali. Mas isso leva bastante tempo.

Muitas pessoas dizem - foi dito isso sobre São Paulo $^{30}$ e dizemos o mesmo em Nova York - que a cidade muda da noite para o dia, você acorda um dia e Nova York está diferente. Mas, na verdade, leva muito tempo, porque há inúmeros conflitos. Nos Países Baixos, o Estado é dono dos terrenos, bem como em Helsinque, onde o Estado também é dono de quase toda a terra urbana. Em Nova York, o Estado não é dono do local do World Trade Center, isso é verdade. Mas leva muitíssimos anos para resolver todos esses problemas, o papel do investimento privado, o investimento público, as leis e a propriedade dos terrenos. Os residentes locais têm alguma voz, mas não muita. E naquela área, os distritos ao redor, como Chinatown, queriam ter alguma participação, porque eles estão tão próximos geograficamente que seus negócios foram afetados por causa da circulação de tráfego limitada; eles queriam algum benefício com a reconstrução.

Mas cada pequeno espaço na cidade exige muitas decisões diferentes, e cada uma delas traz muitos conflitos de interesse que precisam ser resolvidos. Portanto, embora imaginemos que a cidade mude da noite para o dia, na realidade, leva muito tempo para a cidade mudar.

\section{Notas}

1 Com enfoques mais recentes em Amsterdã e Xangai, como mostrará a entrevista.

2 Consolidou-se, a partir daí, e com a participação de outros estudiosos, como Neil Smith (1996), uma série de estudos sobre o conceito de gentrification, cujos prós e contras são avaliados de forma sistemática por Silvana Rubino (2009), autora que propôs a tradução do termo, na língua portuguesa, para "enobrecimento" (ver Zukin, 1996a). Embora suscite reflexões instigantes, tal conceito revela-se também incerto ou limitado quanto ao alcance em pesquisas etnográficas, sobretudo em contextos urbanos distintos do nova-iorquino ou anglo-saxão (Frúgoli Jr. e Sklair, 2013, p. 98).

3 O título sugestivo da introdução é "The city that lost its soul" (Zukin, 2010, p. 1-31).

4 Publicado em português pela Martins Fontes, mas com um título reduzido para Morte e vida de grandes cidades.

5 Engenheiro e planejador urbano responsável pela concepção de uma série de intervenções urbanas de grande porte, sobretudo rodovias, que acarretaram uma escala de demolições avassaladora. Segundo Berman, "o último de uma longa linhagem de construtores e demolidores titânicos, na história e na mitologia cultural" ([1982] 1986, p. 278).

6 Para uma abordagem referencial a respeito, ver o capítulo "Na floresta dos símbolos: algumas notas sobre o modernismo em Nova York" (Berman, [1982] 1986, pp. 271-330). Interessante pensar nas especificidades da difusão das ideias de Jane Jacobs: em pesquisa de campo de Mitchell Duneier (1999, p. 6) em Nova York com vendedores informais das ruas, a grande maioria negra, um vendedor de livros, Hakim Hasan, afirmou ver-se como um "personagem público" [a public character $]$ tal como, segundo ele, nos escritos de Jacobs (1961).

7 Quando participou do simpósio interdisciplinar "Espaço e poder nas grandes metrópoles", ocorrido na Unicamp e organizado por Antônio Arantes; para ler sua conferência, ver Zukin (2000).

8 Do qual Heitor Frúgoli Jr. é integrante, tendo participado da comissão organizadora do referido evento na FAU-USP e convidado Sharon Zukin, que apresentou um paper na sessão "Patrimônio cultural na dimensão metropolitana" (coordenada por Sarah Feldman).

9 Ainda não traduzido no Brasil, cujo título poderia ser traduzido livremente como "Cidade nua" [N.T.]. 
10 Dirigido por Jules Dassin (Estados Unidos, $96 \mathrm{~min}$ ).

11 Uma série de televisão que esteve no ar (na $\mathrm{ABC}$ ) entre 1958 e 1963.

12 Neste parágrafo, os termos story e history foram traduzidos por "história", segundo recomendação de vários dicionários de língua portuguesa [N.T.].

13 Zukin usa a expressão high and low, que significa "em todo canto". Mas aqui ela a usa para indicar uma diferença topográfica (contraste entre arranha-céus e casas antigas) e também social (entre ricos e pobres) [N.T.].

14 High and low em inglês, Céu e inferno em português (Japão, $143 \mathrm{~min}$ ).

15 Ver nota 4.

16 Para mais detalhes, ver Frúgoli Jr. e Spaggiari (2010).

17 Ver, a respeito, <http://libreriearion.it/libri/wp/index. $\mathrm{php} /$ testaccio-da-quartiere-operaio-a-village-della-capitale-intervista-a-irene-ranaldi/>, acessado em 18/12/2013.

18 Sobre este livro, ver Frúgoli Jr. (2005).

19 Publicado no Brasil em 1986 pela Companhia das Letras, cujo título é uma frase de Marx no Manifesto Comunista (Marx e Engels, [1890] 1998).

20 O Bronx, em Nova York.

21 Publicado originalmente em 1990, e em português em 2009, pela editora Boitempo.

22 Sharon Zukin refere-se à já mencionada conferência na FAU-USP.

23 Em 2010, quando S. Zukin e H. Frúgoli Jr. se encontraram em Amsterdã, ela falou da importância do estudo de La Pradelle sobre os mercados de rua (1996) para sua pesquisa.

24 Alimentos permitidos pela lei islâmica.

25 Em tradução livre, algo como "O javali” ou "O porco selvagem" [N.T.].

26 Em geral, trata-se de áreas ou terrenos ainda não explorados urbanisticamente e que atraem as incorporadoras devido ao valor do metro quadrado relativamente mais barato e à ausência de complicações por conta de construçôes anteriores a serem demolidas, por exemplo [N.T.].

27 Para um estudo sobre frequência a museus na região paulistana da Luz, ver Talhari et al. (2012).

28 Para um relato "de perto" de tal evento, ver Frúgoli Jr. (2001).

29 Nome que passou a ser usado, após o 11 de Setembro, para designar o local onde se localizava o World Trade Center [N.T.].
30 S. Zukin possivelmente se refere a um comentário de alguém da plateia (durante a já citada conferência internacional) de que as constantes mudanças em São Paulo lembravam as conhecidas mençôes de Claude Lévi-Strauss a respeito em Tristes trópicos ([1955] 2009, p. 91-100), em que o antropólogo comparava o efeito da passagem do tempo entre as cidades europeias e as cidades do Novo Mundo. Vale dizer que tal comentário gerou então certa discussão, pois nem todos os presentes eram da mesma opinião.

\section{BIBLIOGRAFIA}

BERMAN, Marshall. ([1982] 1986), Tudo que é sólido desmancha no ar: a aventura da modernidade. Tradução de Carlos Felipe Moisés e Ana Maria L. Ioriatti. São Paulo, Companhia das Letras.

DAVIS, Mike. (1990). City of quartz. Londres, Verso.

DE SALVO, Donna. (2001), "New York 19691974”, in I. Blazwick (ed.), Century city: art and culture in the modern metropolis. Catalogue of exhibition at Tate Modern, London, Feb. 1st - Apr. 29th, London, Tate Gallery Publishing.

DUNEIER, Mitchell. (1999), Sidewalk. New York, Farrar, Straus and Giroux.

FRÚGOLI JR., Heitor. (2001), “Nova York nos dias seguintes à tragédia (editorial)". Portal de Arquitetura e Urbanismo Vitruvius, 18. Disponível em <http://www.vitruvius.com.br/revistas/read/arquitextos/02.018/826>.

. (2005), "After the World Trade Center: rethinking New York City (resenha)”. Espaço \& Debates, 46: 157-160.

FRÚGOLI JR., Heitor \& SKLAIR, Jessica. (2013), "O bairro da Luz (São Paulo) e o Bairro Alto (Lisboa) nos entremeios de mudanças e permanências", in C. Fortuna e R. P. Leite (orgs.), Diálogos urbanos: territórios, culturas, patrimónios, Coimbra, Almedina.

FRÚGOLI JR., Heitor \& SPAGGIARI, Enrico. (2010), "Da cracolândia aos noias: percursos etnográficos no bairro da Luz”. Ponto Urbe, 6. Disponível em <http://www.pontourbe.net/ edicao6artigos/118dacracolandiaaosnoiasperc ursosetnograficosnobairrodaluz>. 
HERZFELD, Michael. (2009), Evicted from eternity: the restructuring of modern Rome. Chicago/ Londres, Chicago University Press.

JACOBS, Jane. (1961), The death and life of great American cities. Nova York, Random House.

LA PRADELLE, Michèle de. (1996), Les vendredis de Carpentras: faire son marché, en Provence ou ailleurs. Paris, Fayard.

LEFEBVRE, Henri. ([1968] 1991), O direito à cidade. Tradução de Rubens E. Frias. São Paulo, Moraes.

LÉVI-STRAUSS, Claude. ([1955] 2009), Tristes trópicos. Tradução de Rosa F. D’Aguiar. São Paulo, Cia. das Letras.

MARX, Karl \& ENGELS, Friedrich. ([1890] 1998), Manifesto comunista. São Paulo, Boitempo.

RUBINO, Silvana. (2009), "Enobrecimento urbano", in C. Fortuna e R. P. Leite (orgs.), Plural de cidades: novos léxicos urbanos, Coimbra, Almedina.

SMITH, Neil. (1996), The new urban frontier: gentrification and the revanchist city. Londres/New York, Routledge.

SORKIN, Michael \& ZUKIN, Sharon (eds.). (2002), After the World Trade Center: rethinking New York. Nova York/Londres, Routledge.

TALHARI, Julio C.; SILVEIRA, Laís \& PUCCINELLI, Bruno. (2012), "Reflexões em torno de práticas culturais na Luz". Ponto Urbe, 11 (Dossiê "Luz, São Paulo", organizado por H. Frúgoli Jr.). Disponível em <http://www.pontourbe.net/edicao11-dossie-luz/264-reflexoes-em-torno-de-praticas-culturais-na-luz>.

ZUKIN, Sharon. (1975), Beyond Marx and Tito: theory and practice in Yugoslav socialism. Cambridge, Cambridge University Press. . (1982), Loft living: culture and capital in urban change. New Brunswick, Rutgers University Press.

(1991), Landscapes of power: from Detroit to Disney World. Berkeley/Los Angeles, University of California Press.

. (1995), The cultures of cities. Oxford, Blackwell.

(1996a), "Paisagens urbanas pós-modernas: mapeando cultura e poder". Revista do Patrimônio Artístico e Histórico Nacional, 24: 205-219. (1996b), "Spaces and symbols in an age of decline", in A. D. King (ed.), Re-presenting the city: ethnicity, capital and culture in the 21st-century metropolis, Nova York, New York University Press.

. (2000). "Paisagens do século XXI: notas sobre a mudança social e o espaço urbano", in A. A. Arantes (org.), O espaço da diferença, Campinas, Papirus.

. (2001), "How to create a cultural capital: reflections on urban markets and places", in I. Blazwick (ed.), Century city: art and culture in the modern metropolis. Catalogue of exhibition at Tate Modern, London, Feb. 1st - Apr. 29th, London, Tate Gallery Publishing. . (2002), "Our World Trade Center", in M. Sorkin e S. Zukin, S. (eds.), After the World Trade Center: rethinking New York, Nova York/ Londres, Routledge. . (2010), Naked city: the death and life of authentic urban places. Nova York, Oxford University Press. . (2012), "The social production of urban cultural heritage: identity and ecosystem on an Amsterdam shopping street". City, Culture and Society, 3 (4): 281-291. 


\section{ENTRE O TECIDO FÍSICO E SOCIAL DAS CIDADES: ENTREVISTA COM SHARON ZUKIN}

Heitor Frúgoli Jr. e Julio Cesar Talhari

Palavras-chave: Cidade; Paisagem urbana; Consumo cultural; Gentrificação; Autenticidade.

Entrevista concedida em agosto de 2013 quando da passagem de Sharon Zukin por São Paulo para participar da conferência internacional "Patrimônio cultural: memória e intervençōes urbanas" (FAU-USP). Zukin aborda o contexto nova-iorquino com ênfase em seu livro mais recente, Naked city (2010), em que lança um olhar atento às decorrências de vastas intervençôes de reurbanização, analisa os meandros do tema da autenticidade urbana e aprofunda uma visão crítica sobre a influência de Jane Jacobs nos estudos e nas lutas políticas ligadas ao modo de vida urbano nos Estados Unidos. A socióloga também examina as relaçôes dos grandes museus com a cidade e discorre sobre suas recentes pesquisas em Amsterdã e Xangai, em que novas temáticas são incorporadas em suas reflexôes.

\section{BETWEEN THE PHISICAL AND THE SOCIAL FABRIC OF THE CITY: AN INTERVIEW WITH SHARON ZUKIN}

Heitor Frúgoli Jr. and Julio Cesar Talhari

Keywords: City; Urban landscape; Cultural consumption; Gentrification; $\mathrm{Au}$ thenticity.

Interview by Sharon Zukin, given on August 2013 when in Sao Paulo, participating at the international conference "Cities and Architectures: between heritage and memory" (FAU-USP). Zukin addresses the New York context, highlighting her most recent book, Naked City (2010). In it, she makes a careful observation of the results of the widespread interventions of re-urbanization, analyzes the concept of urban authenticity, and presents a deeper critical view over the influence of Jane Jacobs in the studies and political conflicts related to the urban way of life in the United States. The sociologist also examines the relationship between the big museums with the city and explains her recent research in Amsterdam and Shanghai, in which new themes are incorporated in her reflections.

\section{ENTRE LE TISSUS PHYSIQUE ET SOCIAL DES VILLES: ENTRETIEN AVEC SHARON ZUKIN}

\author{
Heitor Frúgoli Jr. et \\ Julio Cesar Talhari
}

Mots-clés: Ville; Paysage urbain; Consommation culturelle; Gentrification; Authenticité.

Il s'agit d'un entretien concédé en août 2013 lors du passage de Sharon Zukin par São Paulo pour participer à la conférence internationale "Patrimoine culturel: mémoire et interventions urbaines" (FAU-USP). Zukin aborde le contexte new-yorkais en srappuyant sur son ouvrage le plus récent, Nakedcity (2010), dans lequel elle lance un regard attentif sur les conséquences des larges interventions des travaux d'urbanisation, analyse les contours du thème de l'authenticité urbaine et approfondit une approche critique sur l'influence de Jane Jacobs sur les études et les luttes politiques liées au mode de vie urbain des États-Unis. La sociologue examine également les rapports des grands musées avec la ville et aborde ses plus récentes recherches à Amsterdam et à Shanghai, dans lesquelles de nouveaux thèmes sont incorporés dans ses réflexions. 